\title{
BERGSON, BACHELARD E SARTRE: TEMPORALIDADE E CONSTITUIÇÃO DO EGO
}

\author{
Simeão Donizeti Sass
}

Universidade Federal de Minas Gerais

Resumo: 0 presente estudo tem por objetivo analisar o tema da temporalidade no pensamento de Bergson, de Bachelard e Sartre. Tal análise será delimitada pela investigação de uma obra de cada pensador. As obras confrontadas serão Introduction à la métaphysique (1903), La dialectique de la durée (1936) e o capítulo de L'Être et le Néant (1945) intitulado 'La Temporalité'. A intenção primordial desse estudo, entretanto, será circunscrever uma discussão ainda mais restrita, qual seja, a importância da noção de temporalidade para a constituição do ego.

Palavras-chave: Tempo; Ego; Psíquico; Consciência.

Abstract: The objective of this study is to analyze the theme of temporality within the thought of Bergson, Bachelard and Sartre. This given analysis will be delimited by the investigation of one piece of work from each thinker. The confronted works will be Introduction à la métaphysique (1903), La dialectique de la durée (1936) and a chapter from L'Être et le Néant (1945) entitled 'La Temporalité'. The primordial intention of this study, however, will be to circumscribe an even more restrict discussion, which is the importance of this temporality notion for ego's construction.

Keywords: Time; Ego; Psychic; Consciousness.

\section{Introdução}

O presente estudo tem por objetivo analisar o tema da temporalidade no pensamento de Bergson, de Bachelard e Sartre. Tal análise será delimitada pela investigação de uma obra de cada pensador. As obras confrontadas serão Introduction à la métaphysique (1903), La dialectique de la durée (1936) e o capítulo de L'Être et le Néant (1945) intitulado 'La Temporalité'. A intenção primordial desse estudo, entretanto, será circunscrever uma discussão ainda mais restrita, qual seja, a importância da noção de temporalidade para a constituição do ego.

Tal estudo pode parecer um tanto deslocado das atuais investigações acerca dessa temática premente da filosofia contemporânea, que encontra nas neurociências um novo e portentoso referencial científico e paradigmático. Quando a Psicologia se baseia nos referidos estudos para revolucionar suas abordagens, divagações 'metafísicas' sobre o ego e o tempo podem parecer 
questões ultrapassadas. Mas, há todo um universo de investigações recentes no campo da Filosofia da Psiquiatria, cuja figura de destaque é K. W. M. (Bill) Fulford, que estão revitalizando as discussões nessas áreas. As contribuições de Bergson, de Heidegger, de Husserl, de Jaspers e outros filósofos para as atuais abordagens fazem reavivar os debates teóricos e filosóficos. Na estrita medida de nossas limitações, vamos demonstrar que a filosofia contemporânea francesa, principalmente a partir da primeira metade do século vinte, discutiu consistentemente questões que ainda conservam sua validade insuperável.

\section{Bergson}

Um dos postulados mais célebres de Bergson é: pensar intuitivamente é pensar em duração. $O$ que nos leva a admitir que as próprias noções constituídas por ele são expressões de fluidez e movimento. Não temos a intenção, neste estudo, portanto, de elaborar uma abordagem exaustiva do tema do ego ligado ao problema da temporalidade. Intentamos, somente, esboçar uma hipótese, qual seja, identificar a pertinência temática referida e a distinção entre Sartre e Bergson no tocante ao modo como o ego é compreendido.

Para esquematizar tal discussão, abordaremos, inicialmente, alguns elementos daquilo que Bergson denomina eu profundo. Para tanto, citaremos três enunciados do filósofo consagrados no Ensaio sobre os dados imediatos da consciência (1888). O primeiro enunciado afirma: 'A duração pura é a forma que toma (prend) a sucessão de nossos estados de consciência quando nosso eu se deixa viver, quando ele se abstém de estabelecer uma separação entre os estados presentes e os estados anteriores' (BERGSON, 1970, p.48)1. A segunda estabelece que 'as contradições inerentes aos problemas da causalidade, da liberdade, em uma palavra, da personalidade, não têm outra origem, e que basta, para eliminá-las, substituir o eu (mor) real, o eu (mor) concreto, à sua representação simbólica' (BERGSON, 1970, p.63). O último enunciado estabelece que 'é da alma inteira que a decisão livre emana, e o ato será tanto mais livre quanto mais a série dinâmica a qual ele se liga tenda a identificar-se com o eu fundamental' (BERGSON, 1970, p.75). Nessas três manifestações bergsonianas, fica evidente a ligação íntima estabelecida entre a totalidade pessoal e a duração na qual ela se encontra. $\mathrm{O}$ eu pessoal, o eu fundamental, a pessoa, a alma inteira, todos esses termos que podem ser compreendidos como figuras de uma mesma realidade, dão-se no fluxo do tempo que escoa sem cessar. Disso podemos concluir que há entre a duração e

\footnotetext{
1 Todas as traduções do Ensaio são de nossa autoria.
} 
a experiência íntima desta a impossível separação. O eu que experiencia sua vida situa-se no tempo que decorre.

Para compreender esse eu pessoal, faz-se necessário intuir a duração. Para esboçar adequadamente uma das principais intuições da filosofia de Bergson, recorreremos aos comentários de Frédéric Worms. A gênese, o desenvolvimento e as aplicações da noção de duração, segundo Worms, definem a obra inteira de Bergson. A duração existe como duração singular. Ela é, em essência, uma noção fluida ou intensiva, que não designa uma coisa, mas um ato composto por diferentes intensidades ou graus. A partir da duração interior ou psicológica, à qual cada um tem acesso de maneira imanente, é necessário conceber, por um alargamento sucessivo, uma diversidade de durações correspondentes aos diversos graus de ser. Todas essas durações participam dessa duração e são acessíveis em sua diferença (WORMS, 2000, p.21).

É célebre o uso da metáfora do elástico, que se estende sem se romper, para ilustrar a duração. Sem ser uma soma de partes justapostas, ela se distende indefinidamente num movimento de prolongamento que não separa radicalmente o antes e o depois, o começo, o meio e o fim. Fazendo uso das palavras do próprio filósofo, em sua conferência Introdução à metafísica, encontramos a seguinte afirmação:

Descartemos, enfim, o espaço que subjaz ao movimento para levar em conta somente o próprio movimento, o ato de tensão ou de extensão, enfim, a mobilidade pura. Teremos desta vez uma imagem mais fiel de nosso desenvolvimento na duração (BERGSON, 1979, p.16).

Tentando conectar as noções de eu profundo e duração, poderíamos esboçar a hipótese de que o eu profundo existe ao modo da duração, totalizando sua temporalidade. Não estabelecendo entre seu passado, seu presente e seu futuro, nenhuma 'solução de continuidade'. O ato livre, por exemplo, brotaria da personalidade inteira, de uma vida que não necessita desprezar seu passado, ignorar seu presente ou abdicar de seu futuro. Em outras palavras, um ato verdadeiramente livre seria a inserção completa do agente no fluxo temporal. Assim, passado, presente e futuro estariam em uma relação de complementariedade. Essa hipótese nos leva ao terceiro aspecto que desejamos destacar: a relação passado-presente-futuro.

Retomar a tese bergsoniana da memória nos ajuda a entender como as clássicas divisões da temporalidade podem ser situadas no fluxo temporal. A metáfora do novelo serve bem a esse propósito. Viver consiste em envelhecer, se tomarmos nossa vida como o fio de um novelo, o tempo que passa é o seu desenrolar, lembrando que nenhum ato é rigorosamente idêntico a outro. Assim, uma pessoa que toma consciência de sua vida somente o faz exercendo 
a capacidade de rememorar o passado em vista de um futuro vislumbrado. $\mathrm{O}$ fio do novelo é como o tempo dessa vida que passa, "pois nosso passado no segue, cresce sem cessar a cada presente que incorpora em seu caminho' (Ibidem). Daí surge a tese clássica: 'consciência significa memória' (Ibidem). Uma consciência que não tivesse presente a si um ato praticado, jamais poderia agir e situar-se no tempo. Disso podemos derivar uma lição: ato repetitivos, como aqueles obsessivos, ou maníacos, poderiam revelar uma disfunção exatamente no funcionamento da memória. Ou seja, uma disfunção da memória revelaria uma desorganização da consciência pessoal. Essa importância da memória, contudo, não significa aos olhos de Bergson uma fixação da consciência no passado. Exatamente porque a temporalidade é fluxo, a memória não se confunde somente com o passado. Consciência, memória e duração podem ser pensados como complementares se o tempo é o que decorre sempre e não o que se coagula em um momento isolado.

O tempo que decorre se dá como movimento, não como instante estático. Podemos, por isso, estabelecer a correlação entre a duração de uma pessoa e suas ações. Ou seja, viver é agir, é inserir-se no fluxo da vida. Assim, o eu que emana de uma ação livre manifesta-se em sua totalidade. Mas, esses atos livres, não são comuns, eles são raros. $\mathrm{O}$ ato livre exige um esforço que só o espírito pode realizar, e esforço é o ato de dar mais do que se tem.

Visivelmente, uma força trabalha diante de nós, procurando se libertar dos obstáculos e ultrapassar-se a si mesma, procurando tirar de si primeiramente tudo o que tem, e depois, mais do que tem: como definir de outra forma o espírito? (BERGSON, 1979, p. 79).

Eu profundo, personalidade, espírito, noções que apontam para um ser que existe na forma da duração e que tem consciência de que tal fluxo vital não pode deixar de enfrentar os desafios que a sociabilidade impõe. Se a liberdade é o ato que emana das profundezas de nossa alma, como manifestação mais fiel de toda nosso ser, tal ato enfrenta o desafio da originalidade em uma realidade que tende a ser repetição é adestramento. $\mathrm{O}$ ato livre 'custa caro' porque ele navega contra a corrente. 'Exprimimo-nos necessariamente por palavras e pensamos sempre no espaço', isto é, vivemos no mundo da descontinuidade e da negação da duração. O mundo da utilidade e da necessidade torna nosso eu arredio ao ato livre, ele nos cria uma carapaça. Com o tempo, criamos um eu para viver na superfície, no contato social que exige uma expressão especializada e pragmática.

$\mathrm{Na}$ duração, no decorrer do tempo, instauram-se divisões e segmentos. É como se em uma música, em um melodioso passar, necessitássemos introduzir marcações, instantes e momentos descontínuos. Como se, tentando conhecer todos os mistérios de uma canção arrebatadora, 
tentássemos repetir sua audição esmiuçando e cristalizando cada compasso. Se a música é uma das melhores metáforas para intuirmos o tempo, o ritmo que lhe serve de estrutura é um movimento irrepetível. Assim como nossa vida, a música que nos fascina, é um todo indecomponível. Se tentássemos repetir a audição sistemática de uma mesma música, somente poderíamos acrescentar uma nova experiência ao conjunto das anteriores. Não conseguimos esgotar o real que flui por um processo exaustivo de análise. O ritmo, portanto, não é a soma dos compassos, ao contrário, ele é a sua totalização indecomponível. Não é somando instantes estanques que poderemos intuir o tempo que corre, a duração real.

Esboçando uma síntese dos argumentos, as noções de eu e de passado podem ser sintetizadas no esforço de intuição do sentido real da duração. Se tempo é fluxo, o eu que vive sintetiza sua temporalidade através de seus atos. $\mathrm{O}$ eu que é obrigado a viver em sociedade e expressar-se segundo os ditames da espacialidade, não se dilui nesse esforço, ele sobrevive, como uma planta que começa a crescer e que é coberta pelas folhas mortas das árvores ao seu derredor. Esse ser, esse eu pessoal, não se dilui, somente fica adormecido, esperando um sopro de vento que o liberte para crescer. Assim, o eu integra o passado em sua vida, não o recusa como um instante de uma outra melodia, ele o assume como momento de uma mesma sinfonia.

\section{Bachelard}

A análise dos argumentos de Bachelard relativos ao problema que delimitamos é crucial para a compreensão da teoria sartriana da temporalidade e de sua importância para a constituição do ego. Na Quarta Parte de O Ser e o Nada, Capítulo 2, seção III, intitulada 'Da qualidade como Reveladora do Ser', Sartre afirma: 'Trata-se, simplesmente, de tentar uma psicanálise das coisas. Foi o que G. Bachelard ensaiou com muito talento em seu livro L'Ean et les rêves' (SARTRE, 1997, p.732). Tal constatação, por si só, exigiria a comparação entre a psicanálise de Bachelard e a psicanálise existencial de Sartre. Não vamos seguir esse caminho. Tentaremos um percurso mais simples, vamos retomar a discussão que Bachelard faz de noções capitais de Bergson. Para tanto, resgataremos os argumentos expostos em $A$ dialética da duraşão (1936). Nessa obra, é a noção de duração bergsoniana que sofre críticas severas. Será também a partir das conclusões dessa crítica que poderemos encontrar a gênese da leitura que Sartre faz de Bergson, de sua teoria da duração, da concepção de eu profundo e do papel que a noção de nada desempenha na reflexão filosófica.

O tom do debate estabelecido por Bachelard, desde a escolha do título da obra, é desafiador. O seu propósito, não menos polêmico: o 'objetivo metafísico' do estudo 'se apresenta como uma propedêutica a uma filosofia do 
repouso' (BACHELARD, 1994, p.5). Se a referida obra não é só uma crítica a Bergson, a referência ao termo duração revela um alvo privilegiado. Nota-se que Bergson não é recusado de forma radical, mas a problematização de sua filosofia se faz de maneira contundente. Como se, num teste científico de uma hipótese, os limites extremos dos desdobramentos da teoria fossem explorados, revelando suas inconsistências.

Os títulos dos capítulos da obra de Bachelard revelam temas que espelham as 'sombras' da teoria da duração: o nada, o tempo dicotomizado da psicologia, as causalidades físicas, a causalidade intelectual, a consolidação temporal, as superposições temporais, as metáforas da duração e a psicanálise pensada a partir da ritmanálise. Contrapondo o fluxo temporal, surge a dialética, conflito entre opostos representados por instantes do tempo que não são partes interpenetráveis, mas expressões de seres ladeados pelas lacunas e pelo espaço divisor. Se a duração é movimento, ela deve ser também repouso, ela deve envolver em si seu contrário.

Tal desafio intenta pensar a duração como ritmo que enlaça o movimento e o repouso, que relaciona o ser e o não ser, que insere na temporalidade os espaços que separam os instantes. Na verdade, esboça-se uma inversão da ontologia temporal: 'longe de os ritmos serem necessariamente fundados numa base temporal bem uniforme e regular, os fenômenos da duração é que são construídos com ritmos' (BACHELARD, 1994, p.8-9). Vemos aqui a retomada do problema clássico das relações entre o ser e o não ser, do esforço e da fadiga, do fluxo e do intervalo, da alegria e da tristeza, que se dão no tempo vivido, mas que mutuamente se negam.

Se a vida também é 'vontade de nada fazer', a questão metafísica da possibilidade do não ser deve ser repensada. E, afirma Bachelard: 'fomos assim naturalmente conduzidos a um exame dos poderes negadores do espírito' (BACHELARD, 1994, p.6). Essa intuição já nos aproxima das teses de Sartre. Se o espírito é o ser que capta o tempo, que vive, na verdade, a consciência de estar no tempo, ele também é o ser que pode coagular essa mesma temporalidade. Sendo o tédio a experiência desse modo de inscrever-se no tempo como negação do fluxo, o espírito pode desejar a recusa de escoamento, pode acusar seu cansaço, pode experienciar a melancolia. Se a duração como o absoluto da temporalidade pode ser vivida pelos místicos e pelos reformadores morais, um simples mortal, que anseia e que fracassa na tentativa de ser um herói, pode encontrar o outro lado da intuição do absoluto, esse espírito pode ser a expressão de uma ruptura interna.

Bachelard interpela profundamente a ontologia da temporalidade:

Examinamos de imediato essa negação em sua raiz, reconhecendo que o espírito poderia chocar-se com a vida, opor-se a hábitos inveterados, fazer de algum 
modo o tempo refluir sobre si mesmo para suscitar renovações do ser, retornos a condições iniciais. Por que razão não iríamos considerar as ações negativas e ações positivas do tempo como igualmente importantes? Uma vez que pretendíamos ir o mais depressa possível ao centro metafísico do problema, o que precisava ser fundado era uma dialética do ser na duração (Ibidem).

Para os leitores de Evolução Criadora, a defesa do ser do não ser é um contrassenso, uma contradição de termos. Se devemos, primeiramente, considerar qualquer não ser como algo que existe, para, depois, imprimir-lhe uma qualificação negativa, ou seja, se uma negação é uma dupla afirmação; se é no mundo da linguagem e não ontologicamente que essa operação pode ser realizada, a proposta de Bachelard só pode ser o retorno aos termos de um problema já solucionado.

Porém, é, uma vez mais, para a teoria da temporalidade que Bachelard volta seu olhar, para fundar, não na duração, mas no instante, essa dialética. Segundo o autor, ao conceber os momentos nos quais o tempo não escoa,

na tarefa de esvaziar o tempo vivido daquilo que ele tem de excessivo, natarefa de seriar os diversos planos de fenômenos temporais, percebemos que esses fenômenos não duravam todos do mesmo modo e que a concepção de um tempo único, levando embora nossa alma e as coisas para sempre, só poderia corresponder a uma visão de conjunto que resume de forma muito imperfeita a diversidade temporal dos fenômenos(Ibidem).

Uma das consequências que mais incomodam a Bachelard, na teoria da duração, é seu sentido de plenitude. Aos seus olhos,

a filosofia de Bergson é uma filosofia do pleno e sua psicologia uma psicologia da plenitude. Essa psicologia é tão rica, tão nuançada, tão móvel, que não pode se contradizer; ela confere atividade ao repouso, permanência à função, ganha segurança por meio de todo um jogo de suplementações, que fazem com que o palco psicológico nunca fique vazio e que constituem, assim, meios complementares de confirmação. Nessas condições, a vida não tem como temer um fracasso absoluto (BACHELARD, 1994, p.11).

O tema do fracasso é muito caro ao pensamento de Sartre, e podemos afirmar que é nesse sentido empregado por Bachelard que o espírito se vê envolto por desafios que nem sempre são vencidos. Contraposto ao pleno da intuição da duração que a filosofia bergsoniana expressa, o tédio das horas que se arrastam, faz de Roquentin, anti-herói de $A$ Náusea, o antagonista dos personagens de Proust. E a pergunta que surge é:

por que então não tomar o fracasso em si, nas contradições de suas razões de agir? (...) Teríamos tido assim um exemplo de desordem básica, de uma desordem temporal, de uma desordem espiritual. Basta aliás, aprofundar a psicologia da hesitação para pôr a nu o tecido dos sim e dos não. A vida se opõe à vida, o corpo se devora a si mesmo e a alma se rói (...) também o medo está em nós antes do perigo. Como se compreenderia o perigo sem ele? E a mais 
insidiosa das inquietudes nasce da própria quietude. Quando nada me inquieta, dizia Schopenhauer, é exatamente isso que parece inquietante. Basta materializar um pouco a afetividade ${ }^{2}$ para vê-la ondular (...) Compreende-se por que a psicanálise tenha dado recentemente um lugar importante ao instinto de morte, à necrofilia, à necessidade de perder que dá um sentido novo, muito dialético, à necessidade de apostar (BACHELARD, 1994, p.28-29).

Nessa proposta apresentada por Bachelard, encontramos ainda outro aspecto valorizado por Sartre. Decorrente da tese da negatividade do espírito, surge a irrealidade. Nas palavras de Bachelard,

todo conhecimento preciso conduz a uma aniquilação das aparências, a uma hierarquização dos fenômenos, ao ato de lhes atribuir de algum modo coeficiente de realidade, ou, se preferirmos, de irrealidade. Analisa-se assim o real a golpes de negação. Pensar é fazer abstração de certas experiências, é mergulhá-las voluntariamente na sombra do nada (BACHELARD, 1994, p.23).

Nessas palavras de Bachelard poderíamos encontrar a antecipação da ontologia da negação erigida por Sartre em O Ser e o Nada? Por que não? Mencionando a obra Filosofia do inconsciente de Von Hartmann, Bachelard relembra que toda vontade pode ser dupla negação, quando se mostra como disposição para continuar e, ao mesmo tempo, desejo de vencer o medo de não continuar.

Para Bachelard, 'nem sempre uma ação é positiva, e, no próprio plano da ação psicológica, no domínio das funções psicológicas, podemos captar uma dialética que transponha ainda a dialética do ser e do nada' (BACHELARD, 1994, p.27). Se a filosofia bergsoniana destacava a harmonia que superava a tensão do esforço, agora, é o 'tempo da hesitação' (BACHELARD, 1994, p.31) que merece toda a atenção. Se a psicologia derivada da temporalidade bergsoniana possibilitava uma profunda reflexão acerca da totalidade movente que a pessoa humana vivia, a temporalidade rítmica recoloca a tensão entre o passado e o presente. 'O tempo é então contínuo como possibilidade, como nada. Ele é descontínuo como ser (...) partimos não de uma unidade, mas de uma dualidade temporal' (Ibidem).

A importância dada por Bachelard ao nada, ao movimento dialético da realidade, que, nesse aspecto, contrapõe-se ao modo de ser da duração, parece antecipar a ontologia de O Ser e o Nada:

tomada em qualquer uma de suas características, tomada na soma de suas características, a alma não sente, não pensa, não reflete, nem deseja continuamente. Ela não continua a ser. Por que ir buscar o nada mais longe, por que ir busca-lo nas coisas? Ele está em nós mesmos, espalhado ao longo de nossa duração, interrompendo em cada instante nosso amor, nossa fé, nossa vontade, nosso pensamento. Nossa hesitação temporal é ontológica. A

2 Sartre escreveu uma obra relevante sobre esse tema: o Esboço de uma teoria das emoções (1939). 
experiência positiva do nada em nós mesmos só contribui para esclarecer nos sa experiência da sucessão (BACHELARD, 1994, p.34).

Após a contraposição entre dialética e duração, Bachelard explora a concepção de Pierre Janet. E a frase inicial do segundo capítulo da obra em tela representa um verdadeiro programa científico: 'para Pierre Janet, saber é sempre ensinar' (BACHELARD, 1994, p.36). A crítica de Janet ao modo como Bergson organiza a temporalidade serve para a construção de uma nova psicologia, pois
a primeira característica encontrada por um psicólogo cuidadoso no exame dos fenômenos temporais traz o signo da dualidade fundamental da duração. Desde a primeira experiência, com efeito, o tempo aparece para Pierre Janet como obstáculo ou como auxílio; é preciso nos defendermos dele ou utilizá-lo conforme nos localizemos na duração vazia ou no instante realizador (...) $\mathrm{O}$ ser alternativamente perde e ganha no tempo; a consciência se realiza nele ou nele se dissolve. É impossível, portanto, vivenciar o tempo totalmente no presente, ensinar o tempo numa só intuição imediata (BACHELARD, 1994, p.37).

Nessa nova concepção da temporalidade, termos como esperança e inquietação ganham destaque. A harmonia é obrigada a dividir seu fluxo com as rupturas e impasses numa 'ondulação dialética' (Ibidem). O antagonismo se inscreve na contraposição entre vivências prazerosas e tristes, entre a recordação alegre e o temor da repetição de sofrimentos. A temporalidade também se mostra como 'dialética das felicidades e das dores' (BACHELARD, 1994, p.38). Se podemos ver nesses sentimentos o fluxo do tempo, é como contraposição e ruptura entre a felicidade e o torpor que as sucessões ocorrem. A recordação alegre transmuta-se em sofrimento de perda. Uma alegria vivida no passado é facilmente integrada em nossa história de vida, o fracasso, a tragédia, o erro, o insuportável momento de desespero, ao contrário, oscila entre o esquecimento e a tormentosa revivescia de uma memória que deve ser sepultada. Como denominarmos essas heranças? Passado que invade o presente ou história que deve ser superada? Passado que sobrevive ou devir que anseia pela cura das feridas? O sofrimento da perda e a certeza da morte inserem no fluxo temporal lagos de não ser. Como integrar na vida diária a angústia da morte certa? Para aqueles que não acreditam na eternidade da alma, a morte surge como o fim e como aniquilação total. Como aceitar a absoluta duração se o nada mortífero da aniquilação corpórea nos obseda a cada instante? Como manter a esperança se a angústia nos invade? Não seria a morte a derradeira ruptura que desmente toda duração? O sofrimento cinde o tempo dos mortais, numa ruptura irreparável. Nesse sofrimento, o passado que abrigou a perda não é aquilo que nos acalma, mas o tempo que deve ser esquecido, sepultado, ultrapassado, superado. Só podemos superar o sofrimento se superarmos o vivido, deixando-o para trás, nas brumas do ser 
inerte, como uma cicatriz que lembra o ferimento sem revivê-lo. Sem essa ruptura entre o que foi e o que virá, a repetição impossibilita a vida presente e também a futura, transformando-a em sofrimento insistentemente reposto.

Nessa constante reflexão que visa o sentido das vivências, 'conhecernos é reencontrar-nos nessa poeira dos acontecimentos pessoais. É num grupo de decisões experimentadas que repousa nossa pessoa' (BACHELARD, 1994, p.39). A dialética temporal ressalta a decisão, pois sou as escolhas que seccionam minha temporalidade entre prazeres e dores; a duração, por outro lado, parece privilegiar o fluxo de uma pessoalidade que se inscreve na própria temporalidade, como se tempo e subjetividade estivessem inseridos em um mesmo ser. Ser e fluir participam dessa mesma realidade.

Para concluir esse segundo movimento, segundo Bachelard, 'nossa história pessoal nada mais é assim que a narrativa de nossas ações descosidas e, ao contá-la, é por meio de razões, não por meio da duração, que pretendemos dar-lhe continuidade' (Ibidem). A temporalidade surge, portanto, como o locus do conflito e da divisão, na qual existir não significa nos vermos no tempo como em um rio, mas nos inscrevermos na história como em um teatro, no qual nossas ações decidem acerca do que somos.

\section{Sartre}

O terceiro momento deste estudo visa expor alguns dos elementos da teoria sartriana do ego e sua relação com a temporalidade. Como ficou evidenciado nos dois momentos anteriores, tal discussão ocupou um espaço significativo na filosofia contemporânea francesa. Isso se deve também aos embates que cercaram a constituição da Psicologia como ciência, desde o seu início. Pierre Janet e Freud constituíram os polos de uma relevante discussão acerca dos fundamentos da teoria e da terapia envolvendo a psique. No caso de Sartre, esses dois precursores foram igualmente importantes para a sua formação e para a chamada psicanálise existencial. Não temos condições de expor detalhadamente as bases dessa psicanálise erigida por Sartre. Somente temos por objetivo fundamental demonstrar que o debate contribuiu muito para a elaboração dessa psicanálise que se transformou em uma proposta metodológica inscrita no que podemos chamar de psicologia compreensiva.

Buscando erigir a 'psicanálise das coisas', Sartre inscreve-se na esteira da proposta de Bachelard, assim como nas críticas feitas ao pensamento de Bergson. Tal inscrição, contudo, guarda consideráveis reservas e distinções. Sartre visa repensar o próprio método das ciências humanas quando formula sua psicanálise, projeto elaborado em sua obra Questões de método, publicada juntamente com a Crítica da razãa dialética (1960). A crítica da substancialidade do ego, contudo, já figurava no ideário sartriano desde a aparição de $A$ 
Transcendência do ego (1936). A evolução da tese da constituição do ego como objeto psíquico transcendente, contudo, foi complementada com a elaboração da teoria do circuito de ipseidade, nas páginas de O Ser e o Nada.

Não vamos desenvolver tal teoria, escolhemos seguir o percurso da correlação que a noção de ego estabelece com a temporalidade. Assim, privilegiaremos o capítulo de O Ser e o Nada que aborda essa temática. Nesse capítulo, destacaremos a seção III, 'Temporalidade Original e Temporalidade psíquica: A Reflexão'. Como o título indica, a reflexão surge como projeto da consciência de ser plena consciência de si, ser reflexão acabada e plena, sem retornar ao momento vivido, o pré-reflexivo. Tal projeto revela-se um fracasso porque a intencionalidade impede tal 'cristalização' em um momento específico da temporalidade. Mas, o que nos interessa é exatamente a distinção entre original e psíquico.

Tal seção inicia-se com a seguinte afirmação:

o Para-si dura em forma de consciência não-tética de durar. Mas posso 'sentir o
tempo passar' e captar a mim mesmo como unidade de sucessão. Nesse caso,
tenho consciência de durar. Esta consciência é tética e se parece muito com um
conhecimento, tal como a duração que se temporaliza aos meus olhos está
muito próxima a um objeto de conhecimento. Que relação pode existir entre a
temporalidade original e esta temporalidade psíquica que encontro assim que me
apreendo 'durando' [en train de durer]? (SARTRE, 1997, p.208).

A referência ao pensamento bergsoniano e ao termo capital de sua filosofia é evidente. Mas, o modo como ele surge já índica a peculiaridade do tratamento da questão. A vivência do tempo que flui sofre a ação reflexiva da consciência intencional. Em outras palavras, Bergson passa a ser analisado a partir dos referenciais da ontologia fenomenológica. Em outros termos, a temporalidade bergsoniana passa a ser compreendida a partir do contato íntimo que a consciência tem com suas vivências; a temporalidade original, por sua vez, será concebida a partir da historicidade da consciência, temporalidade que não se confunde com a dimensão da psique. Ou seja, há a temporalidade das vivências psíquicas, das emoções, por exemplo, e a temporalidade da consciência que transcende tal 'intimidade', dado que toda consciência é intencionalidade do mundo, isto é, vida histórica que ultrapassa a pura interioridade. Com essa classificação, Sartre visa distinguir a totalidade que é a consciência de um de seus momentos, desse campo específico, que é a vida psíquica. A consciência, campo transcendental impessoaß ${ }^{\beta}$, torna possível o que se denomina psique, sem ser reduzida a essa dimensão. A distinção entre ego (objeto psíquico transcendente e não uma 'propriedade' da pessoa) e consciência, operada desde os anos trinta, tinha por objetivo exatamente tornar

${ }^{3}$ Formulação que remete aos princípios formulados em A Transcendência do ego. 
a consciência o modo de ser da realidade humana, sem os inconvenientes da identificação com a interioridade. A consciência torna-se, então, negação de uma interioridade fundante. $\mathrm{O}$ que significa situar a transcendência como sua maneira de ser primeva. Isso não quer dizer que a consciência da interioridade seja aniquilada, ao contrário, ela passa a ser fenômeno exatamente porque a intencionalidade torna possível a consciência da exterioridade do ser. Quando a abordagem acerca da existência de outra consciência for feita, na terceira parte da obra magna de Sartre, o circuito será completado e a interioridade será concebida em sua correlação com a exterioridade, com o ser-de-outrem. $\mathrm{O}$ que deve ser superado é, exatamente, a organização do problema nos moldes bergsonianos. Não vamos dedicar nosso tempo restante aos contrapontos entre Bergson e Sartre, tal tarefa demanda um estudo acurado e prolongado. Vamos somente tentar esboçar essa distinção entre as duas formas de temporalidade definidas por Sartre.

Para Sartre, a reflexão que o para-si opera, não visa lançar suas sondas em um lago profundo e obscuro, essa atitude é cotidiana.

Aquele que reflexiona sobre mim não é sabe-se lá qual puro olhar intemporal; sou eu, eu que perduro, engajado no circuito de minha ipseidade, em perigo no mundo, com minha historicidade. Simplesmente, esta historicidade, este ser no mundo e esse circuito de ipseidade, o Para-si que sou, vive tudo isso à maneira do desdobramento reflexivo (SARTRE, 1997, p.211).

A temporalidade na qual se inscreve o ser para-si, modo fundamental de ser da consciência, é a historicidade, condição insuperável na qual vive o ser humano, esse ser que perdura na forma da resistência. Se sinto medo ${ }^{4}$, essa consciência amedrontada deve ser compreendida não como uma produção do sujeito por si mesmo, mas como repulsa de seres mundanos que ultrapassam minha interioridade. Até meus desejos são mundanos, não são frutos de impulsos que brotam de uma inconsciente força interior. Toda uma nova concepção das emoções surge da teoria da intencionalidade da consciência que vive no mundo. Consciência que é vivência engajada na historicidade do mundo real, objetivo, que me envolve e que não domino. $O$ tempo da consciência é o tempo do mundo, da história que é feita para além de minhas impressões e que passa a ser as vicissitudes de uma vida com os outros, em meio ao processo de alienação da consciência de si e da constante luta pela existência livre.

Embora o fracasso da reflexão como 'cristalização' seja inevitável, Sartre considera que ela é um dos modos de ser possíveis da consciência. Para

${ }^{4}$ Sartre afirma, em Esboço de uma teoria das emoções (1939), que a emoção é uma consciência irrefletida, assim como em A Imaginação (1936), que a imagem é consciência de algo. 
ser mais precisa nossa descrição, devemos relembrar que existem duas espécies de reflexão:

a reflexão pode ser pura ou impura. A reflexão pura, simples presença do Para-si reflexivo ao Para-si refletido, é ao mesmo tempo forma originária da reflexão e de sua forma ideal; é aquela sobre o fundamento da qual aparece a reflexão impura, e também aquela que jamais é previamente dada, que é preciso alcançar por uma espécie de catarse (SARTRE, 1997, p.213).

É interessante notar que a reflexão pura, no transcorrer das reflexões sartrianas, foi abordada de forma sucinta e esquemática e que a impura foi tratada de maneira muito mais pródiga nas páginas de O Ser e o Nada. Talvez, isso tenha ocorrido por ser a reflexão impura a atitude cotidiana do ser humano que pensa 'ter' emoções como seres em-si. Embora essa parcimônia tenha dificultado o trabalho dos comentadores e estudiosos do existencialismo, fica evidente a importância dada por Sartre ao modo como a consciência se revela em sua espontaneidade. Tal espontaneidade, desde as páginas de $A$ Transcendência do ego, é o traço distintivo da consciência. O que nos leva a pensar na constituição da liberdade como o fundo de seu ser. A reflexão pura visa captar tal espontaneidade em seu ser. Não em momentos estanques ou vivências marcadas pela intimidade, mas no tempo que se dá como a historicidade dessa mesma consciência. Para Sartre, 'a reflexão é o Para-si que tenta recuperar-se como totalidade, em perpétuo inacabamento' (SARTRE, 1997, p.215) e não como aquele que vive a sucessão de tristezas e alegrias; uma sucessão de condutas que podem ser motivos para outros atos ou afecções. Ao modo de afetações que se desenrolam como um novelo.

Historicidade, ser no mundo e circuito de ipseidade podem ser captados coetaneamente pela reflexão se ela se situa na temporalidade originária, existindo em plena liberdade, sem qualquer obrigação de adequar-se a padrões pré-estabelecidos ou premido por impulsos ou afecções. A reflexão pura capta o para-si em seu ser livre.

A reflexão pura continua a descobrir a temporalidade apenas em sua nãosubstancialidade originária; em sua negação de ser Em-si, descobre os possíveis enquanto possiveis, suavizados pela liberdade do Para-si, revela o presente como transcendente, e, se o passado lhe aparece como Em-si, ainda é sobre o fundamento da presença. Por fim, descobre o Para-si em sua totalidade destotalizada como individualidade incomparável que é ela mesma à maneira de ter-de-sê-lo (...) A reflexão, portanto, capta a temporalidade na medida em que esta se revela como o modo de ser único e incomparável de uma ipseidade, ou seja, como historicidade (SARTRE, 1997, p.216-217).

Essa exposição sucinta das características da reflexão pura sintetiza os ganhos que a teoria sartriana da consciência e do ego revelam em relação a alguns dos principais filósofos do pensamento contemporâneo. Principalmente 
em relação a Bergson. A temporalidade passa a ser considerada a partir da historicidade que se vê imersa na existência concreta, no embate que representa o ser histórico. Não há mais a distinção entre o eu profundo e o superficial, como se, no refúgio da intimidade, cada pessoa pudesse encontrar seu verdadeiro eu, liberado através de ações livres e raras. Para Sartre, não podemos isolar nossa vida. Não podemos nos fechar em um casulo. Não podemos nem nos definir de uma vez por todas, exatamente porque a historicidade de nossas ações confere a nosso ser uma precariedade ontológica. O ser humano é diaspórico, ele sempre está em outro lugar, adiante desse mesmo ser, como projeto. Somente a reflexão pura pode captar esse ser que nunca se coagula ou se determina completamente. É aqui que a negação, vislumbrada por Bachelard, ganha todo seu peso. A ontologia da positividade não consegue captar esse modo de ser que jamais se encontra, que nunca descansa, que é pura inquietação, que nunca trilha o caminho do retorno sereno e definitivo a si. Que nunca é um ser em-si. Se a alegria é possível a Bergson, para Sartre, ela sempre vem acompanhada de uma insuperável inquietação de não ser perene. Um bom exemplo dessa inquietação é o personagem Garcin, em Huis clos. Mesmo tentando se desvencilhar da disputa entre Inês e Estelle, ele se vê, contra a vontade, envolto em uma rede de intrigas que o prende como teia de aranha. Não podemos fugir do mundo afundando-nos em nossa subjetividade. Nosso ego não existe ao modo de um lago que se perde nas profundezas do inconsciente. A intimidade não é refúgio porque ela existe somente como um dos polos da consciência, cuja face outra é a convivência social. Para Sartre, cada ego é fruto desse embate entre si mesmo e a alteridade que encarna o mundo. Assim, o tempo não é intimidade, não somos a distensão de nosso passado, não somos seres originais diferenciandonos dos outros, os profetas, os santos e os gênios não se fazem por simplesmente deixarem fluir uma singularidade excepcional; eles se fazem, para Sartre, no mundo e contra o mundo. No fundo da reforma moral que pessoas inigualáveis exemplificam, reside a luta contra si e contra forças antagônicas alheias. A subjetividade é ipseidade que se constitui no seu contraponto com o mundo. O ego é um objeto psíquico transcendente que se dá na relação entre a ipseidade e o mundo circundante. $\mathrm{O}$ ego não é o habitante da consciência, ele é o resultado de um processo de tomada de consciência que passa pela assunção da temporalidade histórica. O que Bergson alcança 'é o psíquico, não a consciência concebida como Para-si' (SARTRE, 1997, p.226).

Para finalizar, a temporalidade psíquica, que pode ser captada pela reflexão impura, é a 'duração psicológica que conhecemos e de que fazemos uso cotidianamente, como sucessão de formas temporais organizadas, é o oposto da historicidade' (SARTRE, 1997, p. 217). As emoções, os 
sentimentos, todo o mundo da sensibilidade existe nessa dimensão da temporalidade e podem ser captados como momentos, partes decomponíveis ou que se sucedem em nossa vida. Uma alegria vivida pode ser acompanhada de uma tristeza, ou seja, a vida psíquica inscreve-se nesse modo de durar que se assemelha a seres determinados e identificáveis. Estava triste, estou alegre, serei mais corajoso na próxima batalha. Essa temporalidade das vivências coexiste na historicidade humana como as figuras de um tapete. Elas são as partes de uma totalidade mais abrangente. Mas, elas somente ganham existência em uma temporalidade que a sustenta e que as envolve. Sartre não abole a duração bergsoniana, ele a restringe ao mundo da vivência interna. Em suas palavras:

Não poderíamos chamar de ilusão esta duração psíquica constituída pela fluência concreta de organizações autônomas, ou seja, em suma, pela sucessão de fatos psíquicos, fatos de consciência: é sua realidade, com efeito, que constitui o objeto da psicologia '(SARTRE, 1997, p.217).

Notamos aqui a distinção entre as aplicações da temporalidade, a psíquica que deve ser investigada pela ciência Psicologia, e, a originária, que deve ser perquirida pela ontologia fenomenológica. Sartre reserva a Bergson o papel de ter circunscrito o modo de acesso ao campo da vida psíquica. Descrito com maestria nas obras de Proust. Faltava revelar que esse não era o último plano da vida pessoal, era preciso situar a consciência, descrever o campo transcendental impessoal, o ser no qual tal vida se insere.

\section{Conclusão}

Ao final dessa exposição, podemos estabelecer que a investigação da temporalidade iniciada com Bergson, com a intuição da duração, foi o ponto de partida de indeléveis perquirições acerca do ego e de suas relações com o fluxo temporal. Tal proposta foi analisada e criticada por Bachelard, primeiramente, destacando as possíveis incongruências de uma descrição do tempo como duração absoluta. Tal crítica tentou destacar que esse ritmo, essa melodia que transcorria como música celestial, era composta por momentos de fluxo e de contra fluxo, de silêncio e de instrumentalidade, em suma, por uma contraposição entre o ser e o não ser. A duração mostrava-se em sua dialética como jogo de oposições. Sartre, atento aos mestres do pensamento francês, conduziu a crítica de Bachelard aos seus limites, introduzindo na temporalidade bergsoniana a distinção entre a temporalidade psíquica e o fundo de ser que a tornava possível, a temporalidade originária. Tal percurso, revelou que Bergson iniciou um campo de pesquisas envolvendo a Filosofia e a Psicologia que até hoje faz brotar novas perspectivas. Reafirmou também sua importância singular para a filosofia contemporânea. 


\section{Referências Bibliográficas}

BACHELARD, G. A dialética da duração. Tradução de Marcelo Coelho. São Paulo: Ática, 1994. . La dialectique de la durée. Paris: Presses Universitaires de France, 1950.

BERGSON, H. Cartas, conferências e outros escritos. Tradução de Franklin L. e Silva e Nathanael Caxeiro. São Paulo: Abril Cultural, 1979.

- Essai sur les données immédiates de la conscience. Paris: Presses

Universitaires de France, 1970. . La pensée et le mouvant. Paris: Presses Universitaires de France, 1969.

FULFORD, B. Oxford Textbook of Philosophy and Psychiatry. Oxford: Oxford University Press, 2006.

SARTRE, J.-P. Critique de la raison dialectique. Paris: Gallimard, 1960. . Esquisse d'une théorie des émotions. Paris: Hermann, 1939. . Huis clos. Paris: Gallimard, 1944.

. L'Être et le Néant. Paris: Gallimard, 1945. . L'Imagination. Paris: Librairie Félix Alcan, 1936. . O Ser e o Nada. Tradução de Paulo Perdigão. Petrópolis: Vozes, 1997.

WORMS, F. Le vocabulaire de Bergson. Paris: Ellipses, 2000. 